\title{
A Comparative Study of Two Treatment Protocols Using Immediate Loading Implants in the Rehabilitation of the Edentulous Jaws with Full Fixed Prostheses: 1 Year Interim Results
}

\author{
Vasina $\mathrm{M}^{1 *}$, Ghirlanda $\mathrm{G}^{1}$ and Borgonovo $\mathrm{AE}$ \\ ${ }^{1}$ Private Practice, Italy \\ ${ }^{2}$ University of Milan, Italy
}

Research Article

Volume 6 Issue 2

Received Date: March 12, 2021

Published Date: April 14, 2021

DOI: $10.23880 /$ oajds-16000292

*Corresponding author: Vasina Michele, Private Practice, Ravenna, Via Mantova 1, Rome, 00198, Italy, Tel: +393408054585; Email: michele.vasina@hotmail.it

\section{Abstract}

Purpose: The aim of this study was to retrospectly evaluate the clinical and radiographic outcomes of two different protocols of immediate full-arch fixed prosthesis supported by implants after 1 year of loading.

Material and Methods: Fifty-five patients received a fixed full-arch rehabilitation supported by implants (total 328 implants). In G1 (32 rehabilitations) with an immediate temporary implant-fixed prostheses (reinforced PMMA) within 3/4 hours from the surgery, the definitive restorations were placed 6 months later. In G2 (30 rehabilitations) with a definitive implant-fixed prostheses made by a milled CAD-CAM bar within 72 hours from the surgery. Clinical and radiographic 1-year data were collected for the groups and statistically compared on patient level: marginal bone loss (MBL), implant-cumulative success rate (I-CSR), prostheses-cumulative success rate (P-CSR) were analyzed.

Results: The 1-year MBL was $(0.80 \pm 0.67) \mathrm{mm}$ in the G1 and $(1.31 \pm 0.93) \mathrm{mm}$ in the G2. The total I-CSR at 1 year is $92.98 \%$. However, this figure should be broken down into the cumulative success of G1 (97.56\%) and G2 (85.98\%). A total of 4 prosthetic complications have been recorded on 62 rehabilitations (93.55\% P-CSR). The fracture of the reinforced PMMA prosthesis was presented in only one case of 32 rehab in the G1, in upper jaw, with an absolute success rate of $96.8 \%$.

Conclusion: The good clinical and radiographic results one year after loading offer promising results on the new materials studied. Further longer follow-up studies are needed to validate these results.

Keywords: Implant-supported fixed prosthesis; Edentulous arches; Dental implants; Immediate loading

Abbreviations: MBL: Marginal Bone Loss; I-CSR: ImplantCumulative Success Rate; P-CSR: Prostheses-Cumulative Success Rate; STROBE: Strengthening the Reporting of Observational Studies in Epidemiology.

\section{Introduction}

The introduction of immediate function in implant dentistry was an important landmark, as it induces important 


\section{Open Access Journal of Dental Sciences}

physical and psychological positive effects on the patients benefitting from it Malo, et al. [1], and excellent success rates, technical benefits and the simplification of this procedure has been widely reported in previous systematic reviews [2-5]. Using this treatment modality, long-term high survival rates have been reported with over $94 \%$ at 10 years for fullarch [6,7] over $97 \%$ at 10 years for partial rehabilitations $[8,9]$, and over $95 \%$ with up to 8 to 12 years for single tooth $[10,11]$.

Several authors have reported promising clinical outcomes when placing immediate fixed reconstructions in edentulous patients supported by four splinted implants; immediately loaded full-arch fixed prostheses supported by two axial and two tilted implants in both arches have proven to be a successful long-term treatment option [12].

The immediate loading of tilted implants with a provisional restoration has been proposed as a simpler, more predictable, less expensive, and less time-consuming method to treat the atrophic jaws, the aim of the present retrospective study was to compare, after 1 year in function, a definitive reinforced PMMA resin prosthesis (G1 group) with an immediate definitive milled CAD-CAM metal-framework prosthesis (G2 group) in patients with completely edentulous jaws: the first-one were immediately loaded and supported by axial and tilted implants, the other-one were loaded within 72 hours and supported by only axial implants.

\section{Material and Methods}

All patients in this retrospective study were treated in two clinics between October 2012 and June 2014.The patients who met the inclusion criteria were identified from the medical records. The study was conducted in accordance with the ethical standards of the 1964 Helsinki declaration and its later amendments. The study follows the Strengthening the Reporting of Observational Studies in Epidemiology (STROBE) guidelines [13]. Informed consent was obtained from all individual participants included in the study and the study was approved by the ethics committee of the Catholic University of The Sacre Heart, Rome. The study included 55 patients ( 29 females and 26 males), with an age range of 41 to 85 years and mean age of 63.7 years.

The patients have been divided in 2 groups

- Group 1-Test group (G1): immediate restoration with multiunit abutments and screw retained bridges at abutment level

- Group 2-Control group (G2): restoration with a screw retained milled framework at implant level produced within 72 h upto 7 days after implant placement
The 0-hypothesis of this study has been, that both protocols of the prosthetic restoration show similar results concerning the success rate of the implants and the clinical parameters, like bone loss and soft tissue related complications.

In G1 a minimum of 4 implants has been placed (blueSKY Bredent medical, Senden, Germany), where the posterior implants have been placed tilted, according to the "All-on-four" protocol [14]. The implants have been restored immediately with the corresponding straight and angulated multi-unit abutments (SKY fast \& fixed Abutment, Bredent medical, Senden, Germany).

In G2 a minimum of 4 implants has been placed straight. In the lower jaw the implants have been Replace tapered Groovy RP (Nobel Biocare) and in the upper jaw with Nobel Speedy Groovy (Nobel Biocare). These implants have been restored with milled frameworks at implant level were us abutments are used that are fused with the bar of the prosthetic structure.

\section{Inclusion and Exclusion Criteria}

Inclusion criteria: Informed consent for the participants; bleeding values at the survey (BOP) and plaque index (PI), recorded in 6 sites on all the residual elements, less than or equal to $20 \%$; residual alveolar ridge of at least $5 \mathrm{~mm}$ in height and $4 \mathrm{~mm}$ in width, stable occlusion.

Exclusion criteria: General medical condition of class III or IV ASA (American Society of Anesthesiologist) and /or psychiatric contraindications [15]; Pregnant or lactating women; absence of teeth/prosthesis in the opposite arch; severe bruxism; radiant therapy of the head/neck district in the previous 5 years; untreated periodontitis; oral hygiene and scarce motivation; impossibility to perform preestablished check-ups.

\section{Surgical Protocol}

Antibiotic prophylaxis was administered as a single dose of $2 \mathrm{~g}$ antibiotic (amoxicillin and clavulanic acid, Augmentin, GlaxoSmithKline, Italy), 1 hour before surgery [16]. Antibiotic therapy continued with the same antibiotic for the next 5 days. Patients were instructed to perform rinses, not diluted with water, with $0.2 \%$ chlorhexidine (Curasept, Curaden Healthcare, Milan, Italy) for 1 min, twice a day, starting 3 days before surgery and subsequently for 2 weeks. Local anesthesia was induced using a $4 \%$ concentration of articaine hydrochloride with 1: 100.000 epinephrine.

A crestal incision is performed in the area of interest and a muco-periosteal flap is raised, exposing the bone portion. 


\section{Open Access Journal of Dental Sciences}

The compromised teeth, considered hopeless, are extracted atraumatically and the alveoli are carefully washed away from any inflammatory residues or from soft tissue portions. The implants were inserted avoiding the tapping of the implant site. The diameter of the final drill was chosen in relation to the quality of the bone, in order to optimize primary stability, to achieve an insertion torque of at least $30 \mathrm{Ncm}$, an essential value to obtain primary stability in immediate loading [5,1719].

G1: In the lower jaw the patients received 4 implants $(2$ straight and 2 tilted) and in the upper jaw (4 straight and 2 tilted). Immediately the multi-unit abutments have been placed and within $3-4$ hours the provisional restoration was fixed on the abutment.

G2: According to the available bone 4 to 6 implants have been placed straight in the upper or lower jaw. After impression taking the implants have been covered with a cover screw. The flap was finally sutured with a non-absorbable 5-0 suture thread (monofilament, nylon) in order to obtain a closure by first intention in order to promote healing.

After surgery, all patients received specific postoperative recommendations, both in writing and orally. A painkiller, ibuprofen $600 \mathrm{mg}$, has been prescribed as needed every $6 / 8$ hours. Synthetic ice has been prescribed for the first two days, to be placed outside the intervention area.

\section{Immediate and Final Prosthetic Protocol}

G1: Patients receive, within 3-4 hours, a prosthesis in reinforced acrylic resin (polymethyl methacrylate, PMMA) screw retained onto the multi-unit abutments. All centric and lateral contacts are checked using a $40 \mu \mathrm{m}$ articulating paper (Bausch Articulating Paper, Köln, Germany) and corrected until a uniform distribution is achieved over the entire prosthetic arch. After at least 6 months after the initial load, in the absence of any signs of inflammation or pain, the temporary prosthesis was replaced by a final screw-retained prosthesis.

G2: The patients in the control group received within 72 hours to 7 days the definite restoration in form of a Toronto bridge, which consists of a metal framework covered with resin, housed and screwed directly onto the implant platform, both lower and upper. This time is necessary for the laboratory phases, in which the realization of the prosthetic device takes place, since it requires milling from the CAD-CAM. All centric and lateral contacts are checked using a $40 \mu \mathrm{m}$ articulating paper (Bausch Articulating Paper, Köln, Germany) and corrected until a uniform distribution is achieved over the entire prosthetic arch.

\section{Follow-Up}

In the month following the surgery, the patients were seen once every 2 weeks for check-ups in which the function of the prosthesis and tissue healing were evaluated. At the same time, patients were included in the specific maintenance program for implant patients, which includes professional hygiene sessions every 3 months after surgery, with inserts dedicated to Teflon implant hygiene. The subsequent visits were performed at 3 and 6 months after the intervention, performing a clinical and radiographic check, then continuing at 12 months. Orthopantomograms (Pax-Uni3D, Digital X-ray Imaging System, VATECH) and, when possible, periapical radiographs with Rinn centering, were performed in each of these visits to evaluate the marginal bone resorption for each implant and the bone level general in the follow-up period.

\section{Outcome Measures}

The scientific community agrees that implant survival can no longer be the only factor determining implant success, but peri-implant conditions and bone-crestal stability must also be considered. Furthermore, the prosthetic variables must also be investigated in order to be able to certify the rehabilitation in question as a real success. Therefore, the following variables were analyzed in the study:

a) Cumulative Implant Success Rate (I-CSR): The implant is functionalized and stable (stability is determined using two instruments applying pressure in opposite directions), no sign of peri-implant radiotransparency, no suppuration or pain at the site, no sign of periimplantitis, no persistent neuropathy or paresthesia [20]. The parameters defined by Albrektsson, et al. [21] at "Statements from the Estepona Consensus Meeting on Peri-implantitis" Albrektsson, et al. [21] were used to evaluate whether an implant was affected by periimplantitis. These parameters were subsequently confirmed in January 2017 in two articles resulting from the Consensus Meeting organized by the Journal Periodontology 2000 [22,23].

b) Marginal Bone Loss (MBL) and Delta MBL $(\triangle \mathrm{MBL})$ : All radiographs were inserted into an image analysis software $[24,25]$. The image scale was calibrated using the known implant size: the scale was then confirmed by measuring the implant diameter at 2 different points and measuring the corresponding lengths again. The marginal bone level (the most coronal point of contact between the implant and the bone) was measured both on the mesial and distal aspect. On the tilted implants, the measurement was performed in parallel with the insertion axis of the implant. The implant neck was used as a reference for each measurement. An average of the distal and mesial measurements was made in order to 
have a single value for each implant. Any symmetrical error in the vertical plane can easily be corrected using the thread pitch or the implant length/width as a reference for calibration. Furthermore, the implantabutment interface is an easily detectable reference point for follow-up measures.

c) Cumulative Prosthetic Success Rate (P-CSR): It was considered "prosthetic failure" whenever the function was compromised for any reason.

All biological complications such as peri-implantitis, peri-implant mucositis, bleeding at probing, site suppuration, fistulas, abscesses and all mechanical complications, such as fractures of implants or any of its components have been recorded.

\section{Statistical Analysis}

Since the primary outcome of this study was to evaluate the effect of a temporary prosthesis on the MBL, the sample size was determined using the GPowers 3.1 software [26], considering the MBL reference parameter to one year $(0,9 \pm$ $0.5 \mathrm{~mm}$ ) [27], assuming a 20\% improvement in this value for the G1 compared to the G2, and setting the alpha error 0.05 and a beta error at 0.90 . From these initial values there is a sample number of 133 plants for each group.

The normality of quantitative variables was assessed with the Kolmogorov-Smirnov test. Since the quantitative variables showed a nonparametric distribution, the differences between the groups were tested by the Mann-
Withney or Kruscal Wollice test; the differences between the groups for discontinuous or binomial variables were calculated using the chi-square test and the exact Fisher test. In order to evaluate the bone resorption modalities a linear regression between MBL and time was performed. In order to reduce the bias, all the variables able to influence bone level changes over time have been considered as: morphology of the implant; habitus of smoking; periodontal status before treatment.

\section{Results}

\section{Patients}

During the period between October 2012 and June 2014, 55 patients were consecutively treated for the rehabilitation of an edentulous arch, by inserting 4 or 6 implants for the inferior maxilla and the upper maxilla, both immediately rehabilitated with a prosthetic device with total implant support. The sample description for demographic and clinical variables is shown below. Of 55 patients, 29 were women (52.7\%) and 26 men (47.3\%), with an average age of 63.7 years (range 41 - 85 years). A total of 62 edentulous arches were rehabilitated, 32 (total 51.6\%, 17 maxillae and 15 mandible) in G1e 30 (total 48.4\%, 16 maxillae and 14 mandible) in G2.

All patients had a stable occlusion relationship. The opposite arches are reported in Table 1 . No relationships between implant failure and the status of the opposite arch were found.

\begin{tabular}{|c|c|c|}
\hline & Frequency & $\%$ \\
\hline Natural Teeth & 36 & 11.0 \\
\hline Denture & 14 & 4.3 \\
\hline Fixed partial denture on tooth (FPD) & 104 & 31.7 \\
\hline Fixed partial denture on implants (FPD-implants) & 54 & 16.5 \\
\hline Removable partial denture (RPD) & 22 & 6.7 \\
\hline Overdenture (OVD) & 6 & 1.8 \\
\hline Full Arch on implants & 92 & 28.0 \\
\hline Total & 328 & 100.0 \\
\hline
\end{tabular}

Table 1: Opposite Arch.

For the restoration of each full arch four to six implants have been used. The frequency is shown in Tables $2 \& 3$. In the test group G1 the frequency of only 4 implants has been much higher than in the control group G2, due to the tilted placement of the posterior implants. In all cases the restoration with only 4 implants took place in the lower jaw. In the upper jaw always 6 implants have been used to support the restoration. 


\begin{tabular}{|c|c|c|c|c|c|c|}
\hline \multirow{2}{*}{} & \multicolumn{2}{|c|}{ Total } & \multicolumn{2}{c|}{ Group 1 } & \multicolumn{2}{c|}{ Group 2 } \\
\cline { 2 - 7 } & Frequency & Percentage (\%) & Frequency & Percentage (\%) & Frequency & Percentage (\%) \\
\hline Four implants & 88 & 26.8 & 56 & 34.1 & 32 & 19.5 \\
\hline Six implants & 240 & 73.2 & 108 & 65.9 & 132 & 80.5 \\
\hline Total & 328 & 100 & 164 & 100 & 164 & 100 \\
\hline
\end{tabular}

Table 2: Frequency of restorations with 4 and 6 implants.

\begin{tabular}{|c|c|c|c|c|c|c|}
\hline \multirow{2}{*}{} & \multicolumn{2}{|c|}{ Total } & \multicolumn{2}{c|}{ Group 1 } & \multicolumn{2}{c|}{ Group 2 } \\
\cline { 2 - 7 } & Frequency & Percentage (\%) & Frequency & Percentage (\%) & Frequency & Percentage (\%) \\
\hline Axial implants & 267 & 81.4 & 103 & 62.8 & 164 & 100 \\
\hline Tilted implants & 61 & 18.6 & 61 & 37.2 & - & - \\
\hline Total & 328 & 100 & 164 & 100 & 164 & 100 \\
\hline
\end{tabular}

Table 3: Distribution of tilted and straight implants.

Regarding the implant connections, there is a big difference between the two analyzed groups. In G1 the test group it was possible with the use of the multi-unit abutments to get in $100 \%$ of the cases an internal implant abutment connection in the original precision produced by the implant manufacturer. In G2 the control group this was not possible. Only in $15.9 \%$ of the implants it was possible to produce with CAD/CAM an internal connection which is similar to the original implant abutment connection. In the other $84.1 \%$ of the cases it was necessary due to the angulation of the implants to manufacture an external connection which was only laying on top of the implant and therefore the connection was made by the screw of the restoration (Table 4).

\begin{tabular}{|c|c|c|c|c|c|c|}
\hline & \multicolumn{2}{|c|}{ Total } & \multicolumn{2}{c|}{ Group 1 } & \multicolumn{2}{c|}{ Group 2 } \\
\cline { 2 - 7 } & Frequency & Percentage (\%) & Frequency & \% & Frequency & Percentage (\%) \\
\hline Internal Connection & 190 & 57.9 & 164 & 100 & 26 & 15.9 \\
\hline Tilted implants & 138 & 42.1 & - & - & 138 & 84.1 \\
\hline Total & 328 & 100 & 164 & 100 & 164 & 100 \\
\hline
\end{tabular}

Table 4: Internal versus external connection.

\section{Implant Cumulative Survival Rate}

Implant cumulative success rate (I-CSR) is defined as an implant that presented no complications during the control. In this study they were divided into G1 and G2 by time, as follows in Table 5.

\begin{tabular}{|c|c|c|c|c|c|c|c|c|c|}
\hline & \multicolumn{3}{|c|}{ Total } & \multicolumn{2}{c|}{ Group 1 } & \multicolumn{3}{c|}{ Group 2 } \\
\cline { 2 - 11 } & $\begin{array}{c}\text { w/o } \\
\text { complication }\end{array}$ & $\begin{array}{c}\text { Compli } \\
\text { cation }\end{array}$ & $\begin{array}{c}\text { Percentage } \\
\text { (\%) }\end{array}$ & $\begin{array}{c}\text { w/o compli } \\
\text { cation }\end{array}$ & $\begin{array}{c}\text { Compli } \\
\text { cation }\end{array}$ & $\begin{array}{c}\text { CSR } \\
\text { \% }\end{array}$ & w/o complication & Complication & CSR \% \\
\hline 3 months & 327 & 1 & 99.7 & 164 & & 100 & 163 & 1 & 99.4 \\
\hline 6 months & 317 & 11 & 96.6 & 161 & 3 & 98.2 & 156 & 8 & 95.1 \\
\hline 1 year & 317 & 11 & 96.6 & 163 & 1 & 99.4 & 154 & 10 & 93.9 \\
\hline Total & 328 & 23 & 92.98 & 164 & 4 & 97.56 & 164 & 19 & 86 \\
\hline Implants & & 7 & & & 1 & & & 6 & \\
\hline $\begin{array}{c}\text { other } \\
\text { complication }\end{array}$ & & 16 & & & 3 & & & & 13 \\
\hline
\end{tabular}

Table 5: Implant cumulative success rate. 
The 1 year absolute I-CSR in G1 is $97.56 \%$ against $85.98 \%$ in G2. The difference is not only caused by peri implant tissue complications but also in the loss of implants. 7 implants failed on the 328 inserts. Of these 7 implants, 6 belong to G2 (all axial implants). Three of these implants belong to the same patient (inserted into the upper jaw), the other 3 to two other patients and all were inserted into the mandible. In G1, only 1 implant was removed, thus presenting a 1 yearimplant survival rate of $99.4 \%$ (tilted implant inserted in the maxilla, posterior area).

When an implant has been considered failed, due to mobility or infection, it has been removed. After the healing a new implant has been inserted. Only in one case, a patient of G2, after the failure of 2 implants (out of 6 ) inserted in the mandible did not consent to the substitution but kept only 4 implants with the same modified prosthesis. The implants inserted again were not counted in the statistics.

\section{Marginal Bone Loss (MBL)}

At each control visit (Baseline - 3 months - 6 months - 1 year) an OPT radiograph has been taken. The OPT radiographs were all legible: but in 16 implant sites $(4.9 \%)$ it was not possible to perform the measurement of the marginal bone, either the mesial aspect or the distal one was illegible, never both. Of the 16 unreadable values, 13 were axial implants placed in the infraforaminal area, while 3 were axial implants positioned in the area of the upper lateral incisors. At the baseline, the bone level (Bone Level, BL) around the implants in the two groups are presented in Table 6 .

\begin{tabular}{|c|c|c|}
\hline & G1 & G2 \\
\hline $\mathrm{N}$ & 164 & 164 \\
\hline Min & $-1,904$ & -173 \\
\hline Max & 1,294 & 1,674 \\
\hline Media & -232 & 0,254 \\
\hline Stand dev & 0,657 & 0,696 \\
\hline Variance & 0,431 & 0,485 \\
\hline
\end{tabular}

Table 6: Marginal bone loss (MBL) after 3 years.

The statistical analysis of the MBL of the test group G1 and the control group G2 has been statistically significant difference between the MBL and the different time intervals, shown in Table 7 and in Figure 1.

\begin{tabular}{|c|c|c|}
\hline MBL & $\begin{array}{c}\text { G1 } \\
\text { (164 implants } \\
\text { 32 rehabilitations) ( } * \text { ) }\end{array}$ & $\begin{array}{c}\text { 32 } \\
\text { (164 implants } \\
\text { 30 rehabilitations) ( } * \text { ) }\end{array}$ \\
\hline Initial Bone Level & $-0,23 \pm 0,65 ; 1,29 ;-1,90$ & $0,25 \pm 0,69 ; 1,67 ;-1,73$ \\
\hline 3 months & $0,13 \pm 0,63 ; 1,75 ;-1,77$ & $0,82 \pm 0,50 ; 1,99 ;-1,27$ \\
\hline 6 months & $0,37 \pm 0,58 ; 1,90 ;-1,57$ & $1,2 \pm 0,91 ; 7,83 ;-0,99$ \\
\hline 1 year & $0,58 \pm 0,50 ; 2,41 ;-1,28$ & $1,56 \pm 0,79 ; 7,76 ;-0,36$ \\
\hline$\left(^{*}\right)$ Differences between times: Kruscal Wallis Test $=\mathrm{p}<0,05$ & & \\
\hline
\end{tabular}

Table 7: Marginal bone loss (MBL).

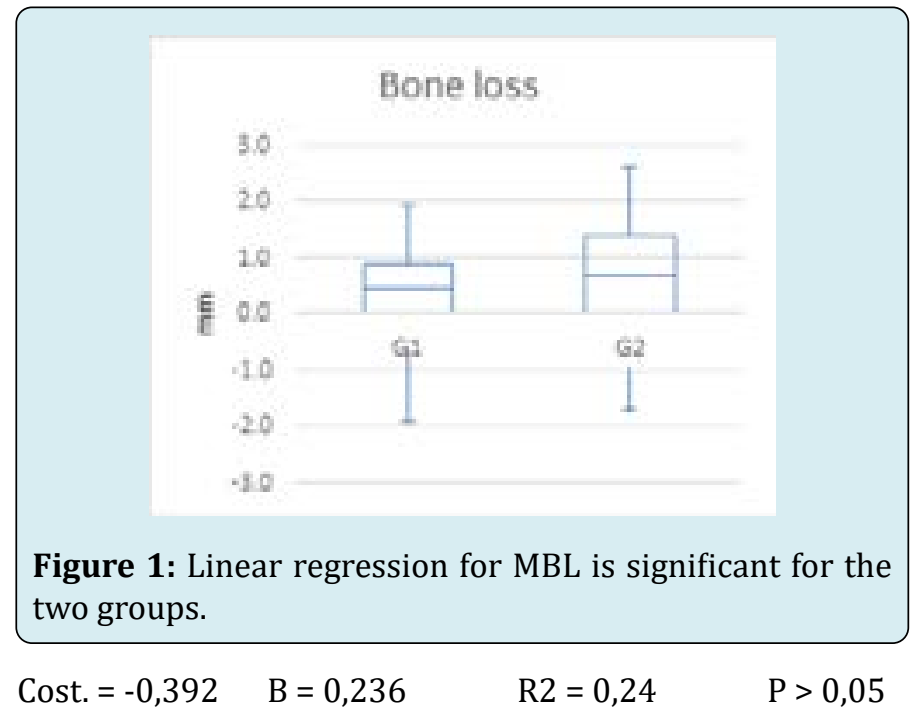

Cost. $=-0,157 \quad B=0,455$

$\mathrm{R} 2=0,34$

$\mathrm{P}>0,05$

The measurement deltas in the various intervals also do not have a normal distribution, as show in Table 8.

\begin{tabular}{|c|c|c|c|c|}
\hline $\mathbf{\Delta M B L}$ & $\begin{array}{c}\mathbf{N}^{\circ} \text { Total } \\
\text { Implants }\end{array}$ & $\begin{array}{c}\text { Test } \\
\text { Group }\end{array}$ & $\begin{array}{c}\text { Control } \\
\text { Group }\end{array}$ & $\begin{array}{c}\mathbf{P} \\
\text { Value }\end{array}$ \\
\hline 3 months & 328 & $\begin{array}{c}0,36 \pm \\
0,49\end{array}$ & $0,56 \pm 0,63$ & $\begin{array}{c}\mathrm{p}< \\
0,05\end{array}$ \\
\hline 6 months & 327 & $\begin{array}{c}0,60 \pm \\
0,65\end{array}$ & $0,99 \pm 0,98$ & $\begin{array}{c}\mathrm{p}< \\
0,05\end{array}$ \\
\hline 1 year & 323 & $\begin{array}{c}0,80 \pm \\
0,67\end{array}$ & $1,31 \pm 0,93$ & $\begin{array}{c}\mathrm{p}< \\
0,05\end{array}$ \\
\hline & & & & \\
\hline
\end{tabular}

Table 8: Delta Marginal Bone Loss. 
Linear regression for MBL deltas is significant for the 2 groups Table 9 and Figure 2 shows the delta MBL trend of G1 (blue line) and G2 (green line) according to time intervals.

$\begin{array}{ll}\text { Cost. }=-0,160 & B=0,235 \\ \text { Cost. }=-0,415 & B=0,458\end{array}$
$\mathrm{R} 2=0,24$

$\mathrm{R} 2=0,32$ $\mathrm{p}<0,05$

$\mathrm{p}<0,05$

\begin{tabular}{|c|c|c|c|c|c|c|}
\hline & \multicolumn{2}{|c|}{ Total } & \multicolumn{2}{c|}{ Group 1 } & \multicolumn{2}{c|}{ Group 2 } \\
\cline { 2 - 7 } & $\begin{array}{c}\text { Prosthetic } \\
\text { complications }\end{array}$ & $\begin{array}{c}\text { Percentage } \\
\text { (\%) }\end{array}$ & $\begin{array}{c}\text { Prosthetic } \\
\text { complications }\end{array}$ & $\begin{array}{c}\text { Percentage } \\
\text { (\%) }\end{array}$ & $\begin{array}{c}\text { Prosthetic } \\
\text { complications }\end{array}$ & $\begin{array}{c}\text { Percentage } \\
\text { (\%) }\end{array}$ \\
\hline $\begin{array}{c}\text { Temporary } \\
\text { Restoration }\end{array}$ & 1 & 1.6 & 1 & 3.1 & 0 & 0 \\
\hline $\begin{array}{c}\text { Definitive } \\
\text { Restoration }\end{array}$ & 3 & 4.8 & 1 & 3.1 & 2 & 6.7 \\
\hline $\begin{array}{c}\text { Total } \\
\text { Restoration }\end{array}$ & 62 & 93.5 & 32 & 93.8 & 30 & 93.3 \\
\hline
\end{tabular}

Table 9: Linear regression.

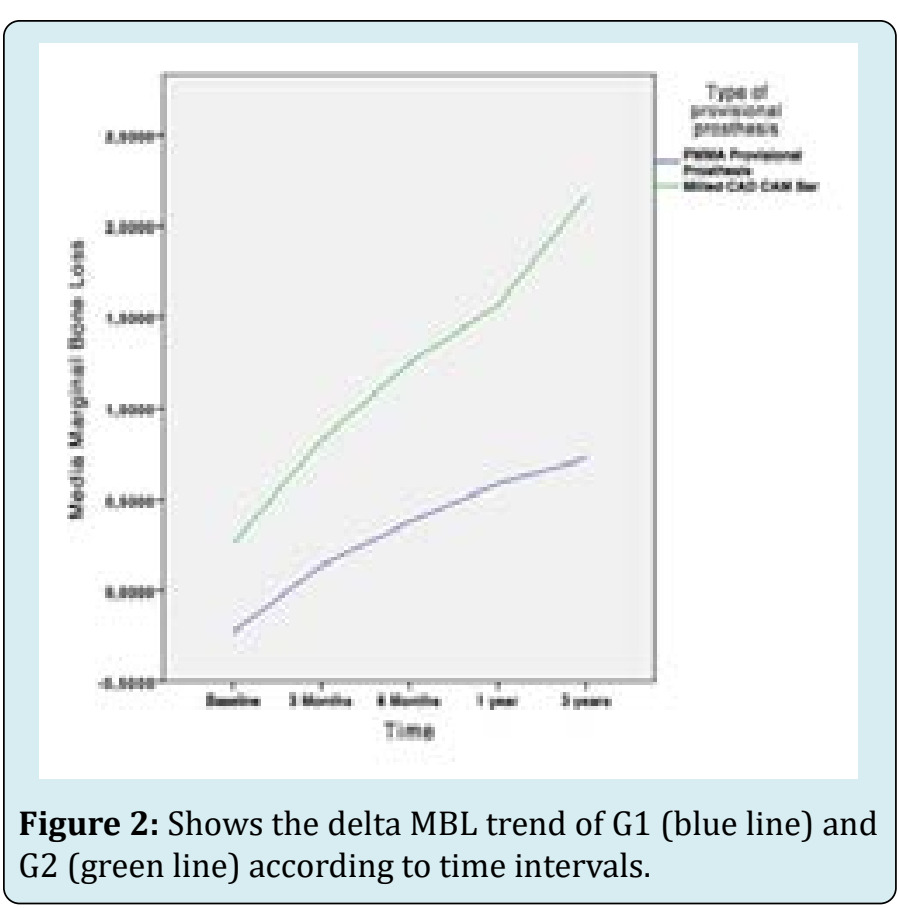

\section{Cumulative Prosthetic Success Rate (P-CSR)}

A total of 4 prosthetic complications -out of 62 rehabilitated arches- were recorded: one fracture of the temporary reinforced PMMA prosthesis occurred in only one case out of 32 rehabilitations in G1 (upper jaw) and 1 fracture of the definitive prosthesis; the fracture of the milled CAD-CAM bar occurred in 2 cases out of 30 rehabilitations in the G2, presenting a success rate of $93.33 \%$.

In one patient out of 55 the prosthetic complication was associated with $\mathrm{n}^{\circ} 1$ failed implant (G2). Two detachments of resinous coating material were recorded, by the way this not affect the patient's function or aesthetics, so they were not counted within the statistics. There were no cases of loosening of the temporary structure.

\section{Discussion}

This retrospective study aimed to investigate and evaluate the clinical and radiographic outcomes of immediate loading implant rehabilitation in patients with at least one edentulous arch. Marginal bone Loss (MBL), implant success (I-CSR) and prosthetic success (SR-prosthesis) were used to compare two different rehabilitation modalities.

One of the disadvantages of the study is certainly its retrospective nature, but fortunately there were no dropouts among patients and all of them presented the necessary information at the programmed controls. In this study $100 \%$ of the radiographs were available at the baseline and according to the strict follow-up protocols, all patients had at least 3 months, 6 months, 1 year radiographs, therefore it was possible to calculate the MBL intercourse. This factor is crucial because, as demonstrated by Browaeys, et al. [28], the average bone loss can vary greatly depending on the periods that are taken into consideration: analyzing this average in 700 implants, loaded within 10 days of insertion with fullarch prosthesis, between 0 and 3 months the authors point out a loss of about $1 \mathrm{~mm}$, while between 3 and 6 months it was close to zero. In our study the values between $0-3$ and 3-6 months were respectively $(0.36 \pm 0.49) \mathrm{mm}$ and $(0.60 \pm$ $0.65) \mathrm{mm}$ in G1 and (0.56 \pm 0.63$) \mathrm{mm}$ and $(0.99 \pm 0.98) \mathrm{mm}$ in G2. These values do not show a clear trend as described by Browaeys, et al. [38] but this value seem to show a continuous remodeling in the first 6 months, which will be attenuated at a 1 year from implant placement.

The difference of MBL around axial and tilted implants at 1 year was not statistically significant. Our result is in line with that of other studies, the observed MBL is modest and comparable with previous studies both for axial and 


\section{Open Access Journal of Dental Sciences}

inclined implants. In a recent systematic review, the MBL for axial implants varied between 0.6 and $1.2 \mathrm{~mm}$ and between 0.34 and $0.92 \mathrm{~mm}$ for inclined implants, with no apparent difference between the mandible and maxillary [29].

Several authors Zechner, et al. [30], Van De Velde, et al. [31], Collaert \& De Bruyn [32], Cooper, et al. [33], Dierens, et al. [34], Vandeweghe, et al. [35] found no statistically significant differences in the bone levels of the mesial and distal sites of the implant, both for intraoral RX and OPT, both at baseline and in follow-ups. Therefore, also the implants in which one of the 2 sites mentioned was illegible were considered in the study.

In a comparative study where intraoral Rx and OPT were compared it was demonstrated that the CEJ (cement enamel junction) was identified with a discrepancy of $0.1 \mathrm{~mm}$ and the results of some studies Sivasriyanond \& Manson-Hing; Brägger, et al. [36,37] in which the authors attested the accuracy of the image of the endoral $\mathrm{Rx}(0.1 \mathrm{~mm})$ higher than the OPT $(0.2 \mathrm{~mm})$, of only $0.1 \mathrm{~mm}$, we asked ourselves about the clinical relevance of differences of $<0.2 \mathrm{~mm}$ and it was decided to use the measurements on digital OPT.

Lambert, et al. [38] defined the learning curve for implant placement, showing that implants inserted by inexperienced operators ( $<50$ implants) fail with a double frequency. In our study, surgical procedures were performed by an operator with more than 20 years of experience in the field of implant surgery ( $>50$ edentulous rehabilitations).

As already reported, the primary stability at the time of implant placement is fundamental for immediate loading and it is reported that insertion torque values below $30 \mathrm{Ncm}$ can lead to implant failure. For this reason, it is not possible to establish a priori a standardized position of the distance between implant-abutment junction and bone peak, since at the time of insertion the clinician can choose to place the implant more coronally/apically depending on what is his experience in order to obtain a correct primary stability.

While in G2 the patients received a permanent prosthesis directly, the patients in G1 received a temporary prosthesis, having in any case the final objective of receiving a definitive rehabilitation after 6-8 months. The incidence of fracture of PMMA-reinforced prostheses in this study was 3.1\% (1/32). Although it is not possible to make a direct comparison with other studies in the literature, as the reinforced PMMA has never been used as material for the temporary prosthesis, it is interesting to report that in the studies where provisional prostheses were delivered in acrylic resin alone or resin acrylics reinforced with metal, the authors reported higher fracture incidences, such as Agliardi, et al. (15.6\%), Francetti, et al. (11\%) and Maló, et al. (27\%).
In our practice, a temporary structure is more appreciated both by the clinician and by the patient, at least in early months. In fact, from the point of view of the clinician it is simpler to manufacture, easily modifiable in case of necessity or easily repairable in case of possible fractures and finally allows to improve the aesthetics following the healing and the maturation of the tissues. The patient appreciates more the use of the provisional protocol because it allows him to receive rehabilitation within 3-4 hours, has a lower cost compared to temporary structures with metal bars, has an excellent appearance and has a lower weight than those reinforced.

In this study, $90.91 \%$ of implant failures (intended as removed implants or with peri-implantitis) occurred in G2, whereas $9.09 \%$ in G1. Some studies report a greater percentage of failure in the maxilla than in the inferior and in our study, although for a few implants (7), considering both the test group and the control group, the percentage is slightly in favor of the maxilla (57\%).

To guarantee the duration of osseointegration, the union (splinting) of two or more implants requires the realization of prostheses that must meet two basic requirements: precision of prosthetic coupling (fitting) and liabilities (passivity of the structure). Ideally a prosthesis should guarantee a correct marginal closure on the abutment (precision of the fit) to limit the marginal bacterial infiltration. At the same time, it should guarantee passive insertion without exerting tension on the implants and therefore on the bone tissue.

However, passivity and fit precision are two characteristics that are difficult to obtain simultaneously. The number of clinical and laboratory steps and the different materials used in the manufacture of implant prostheses are responsible for deformations and therefore errors that are difficult to predict and control. The more the prosthetic bar tends to passivity the more the marginal precision decreases and vice versa, the more the prosthetic bar is precise the less it is passive and the clinician feels high friction on the abutments during insertion. This friction translates into a constant force which is applied to the bone-implant interface and which is added to the masticatory loads: this force is called preload. We must therefore adopt a method that is able to guarantee a good balance between passivity and fit precision, limiting the possibility of generating a potentially harmful preload.

In our study the MUA (inclined or $0^{\circ}$ ) used in G1 are industrial components, therefore standardized and precise, while in the control group the abutments are milled metal structure, therefore produced only after the impression taking. These steps may entail a certain inaccuracy in the milled implant-abutment coupling, which could lead to the 


\section{Open Access Journal of Dental Sciences}

formation of a microgap between the two structures. If we consider that in the industrial production of two mechanical components to be coupled a dimensional error margin $( \pm 10$ $\mu \mathrm{m})$ is tolerated, the accuracy will probably be lower if we add the bar milling variable to this data. Supposing that the best oral hygiene of the patient is given, the possibility that the bacterial plaque accumulates depends on the precision in the abutment-implant connection and on the surface roughness of the abutment. This space, although small, is not cleanable and can easily be colonized by pathogenic bacteria and be a starting point for the development of a possible peri-implant mucositis.

A further variable to consider is the depth of engagement of the two methods. Rehabilitation on a milled bar, in order to have an acceptable engagement depth, should be inserted in systems that are absolutely parallel to one another, otherwise the liability previously described would be lost. This situation is clinically difficult to achieve. For this reason almost all (84\%) of the G2's systems present an external connection and the engagement takes place in a superficial manner. On the contrary, the MUAs are inserted into the implant for a depth of several $\mathrm{mm}$, the passivity is guaranteed as an industrial element, resulting perfectly stable and with micromovements below the threshold values for osseointegration $(<150 \mu \mathrm{m})$.

Moreover, thanks to the presence of MUAs, the connection with the prosthesis takes place at a more coronal level than the control group, where the connection is made directly with the implant platform. This involves: a juxtagingival abutment-prosthesis connection and not at the implant level; the MUAs are inserted into the implant at the time of surgery. This allows a healing of the tissues around what will be the definitive abutments. Furthermore, it is not necessary to remove them during the control visit, or in case the prosthesis should be removed, unlike the G2.

Regarding delivery times, in addition to the advantages already mentioned above, there is an extremely important factor. If the milled metal structure has inconsistencies that do not allow it to be inserted, it is necessary to restart the processes from the impression taking and wait for the delivery times again, which would result in the loading in a phase that may already be critical for osseointegration (as it would have been 7-10 days), a phase that requires the absolute immobility of the prosthetic structure on the implants, under penalty of the failure of the rehabilitation.

Vervaeke, et al. [39] reported the effects of smoking on initial bone remodeling and early implant failure. The study reports 3 times more implant failure in smokers than nonsmokers and the maxilla appear to be more susceptible to MBL than the mandible. In our study there is no statistically significant difference between smokers and non-smokers in terms of implant failure, probably because none of the patients was considered a heavy smoker.

No difference even between patients with previous periodontitis treated and healthy patients in terms of implant failure.

\section{Conclusion}

With the limitations of this study, the success in the medium term of the results obtained seem to confirm that full-arch fixed rehabilitations supported by implants can be considered an effective solution for the rehabilitation of the edentulous patient.

The use of a protocol that foresees the provisional prosthetic rehabilitation in reinforced PMMA seems to show promising results, based on the variables considered in this study: an implant success rate (implants do not show periimplantitis and have not been removed) equal to $97.56 \%$, in contrast with the success rate of $85.98 \%$ of G2. This difference was statistically significant. The 1 -year MBL $(0.8 \pm$ $0.6 \mathrm{~mm}$ ) is lower than the values present in the most recent systematic reviews of the immediate full-arch load $(0.9 \pm 0.5$ $\mathrm{mm})$.

There was only one fracture within 32 rehabilitations of the reinforced PMMA structure, presenting a success rate of $96.9 \%$ temporary rehabilitation, a very high percentage, even comparing it with other studies where solutions without reinforcing metal structure were presented.

\section{References}

1. Maló P, Rangert B, Dvärsäter L (2000) Immediate function of Brånemark implants in the esthetic zone: A retrospective clinical study with 6 months to 4 years of follow-up. Clin Implant Dent Relat Res 2(3): 138-146.

2. Attard NJ, Zarb GA (2005) Immediate and early implant loading protocols: A literature review of clinical studies. J Prosthet Dent 94(3): 242-258.

3. Ioannidou E, Doufexi A (2005) Does Loading Time Affect Implant Survival? A Meta-Analysis of 1,266 Implants. J Periodontol 76(8): 1252-1258.

4. Nkenke E, Fenner M (2006) Indications for immediate loading of implants and implant success. Clin Oral Implants Res 17(2): 19-34.

5. Esposito M, Grusovin MG, Willings M, Coulthard P, Worthington HV (2007) The effectiveness of immediate, early, and conventional loading of dental implants: a 
Cochrane systematic review of randomized controlled clinical trials. International Journal of Oral \& Maxillofacial Implants 22(6): 893-904.

6. Maló P, De Araújo Nobre M (2011) Implants (3.3mm Diameter) for the Rehabilitation of Edentulous Posterior Regions: A Retrospective Clinical Study with Up to 11 Years of Follow-Up. Clin Implant Dent Relat Res 13(2): 95-103.

7. Östman PO, Hellman M, Sennerby L (2012) Ten Years Later: Results from a Prospective Single-Centre Clinical Study on 121 Oxidized (TiUniteTM) Brånemark Implants in 46 Patients. Clin Implant Dent Relat Res 14(6): 852860.

8. Åstrand P, Ahlqvist J, Gunne J, Nilson H (2008) Implant treatment of patients with edentulous jaws: A 20-year follow-up. Clin Implant Dent Relat Res 10(4): 207-217.

9. Degidi M, Nardi D, Piattelli A (2012) 10-Year Follow-Up of Immediately Loaded Implants with TiUnite Porous Anodized Surface. Clin Implant Dent Relat Res 14(6): 828-838.

10. Malo P, Nobre MA, Lopes A, Moss SM, Molina GJ (2011) A longitudinal study of the survival with up to 10 years of follow-up. J Am Dent Assoc 142(3): 310-320.

11. Wolfinger G, Balshi TJ, Wulc DA, Balshi SF (2012) A retrospective analysis of 125 single molar crowns supported by two implants: Longterm follow-up from 3 to 12 years. J Prosthet Dent 107(1): 54.

12. Capelli M, Zuffetti F, Del Fabbro M, Testori T (2007) Immediate rehabilitation of the completely edentulous jaw with fixed prostheses supported by either upright or tilted implants: a multicenter clinical study. Int J Oral Maxillofac Implants 22(4): 639-644.

13. Von Elm E, Altman DG, Egger M, Pocock SJ, Gøtzsche PC, et al. (2007) The Strengthening the Reporting of Observational Studies in Epidemiology (STROBE) statement: Guidelines for reporting observational studies. PLoS Medicine 4(10): 1623-1627.

14. Maló P, Rangert B, Nobre M (2003) "All-on-four" immediate-function concept with brånemark system implants for completely edentulous mandibles: A retrospective clinical study. Clin Implant Dent Relat Res 5(1): 2-9.

15. Keats AS (1978) The ASA Classification of Physical Status-A Recapitulation. Anesthesiology 49(4): 233235.

16. Esposito M, Grusovin MG, Loli V, Coulthard P, Worthington
HV (2010) Does antibiotic prophylaxis at implant placement decrease early implant failures? A Cochrane systematic review. Eur J Oral Implantol 3(2): 101-110.

17. Javed F, Romanos GE (2010) The role of primary stability for successful immediate loading of dental implants. A literature review. J Dent 38(8): 612-620.

18. Maló P, De Araújo Nobre M, Lopes A, Francischone C, Rigolizzo M (2012) "All-on-4" Immediate-Function Concept for Completely Edentulous Maxillae: A Clinical Report on the Medium (3 Years) and Long-Term (5 Years) Outcomes. Clin Implant Dent Relat Res 14(1): 139-150.

19. Gallucci G, Benic G, Eckert S, Papaspyridakos P, Schimmel $M$, et al. (2014) Consensus Statements and Clinical Recommendations for Implant Loading Protocols. Inter J Oral Maxillofac Implants 29: 287-290.

20. Steenberghe D van (1997) Outcomes and Their Measurement in Clinical Trials of Endosseous Oral Implants. Ann Periodontol 2(1): 291-298.

21. Albrektsson T, Buser D, Chen ST, Cochran D, Debruyn H, et al. (2012) Statements from the Estepona Consensus Meeting on Peri-implantitis, February 2-4, 2012. Clin Implant Dent Relat Res 14(6): 781-782.

22. Albrektsson T, Chrcanovic B, Östman PO, Sennerby L (2017) Initial and long-term crestal bone responses to modern dental implants. Periodontol 2000 73(1): 41-50.

23. Coli P, Christiaens V, Sennerby L, Bruyn H De (2017) Reliability of periodontal diagnostic tools for monitoring peri-implant health and disease. Periodontol 2000 73(1): 203-217.

24. Schindelin J, Rueden CT, Hiner MC, Eliceiri KW (2015) The ImageJ ecosystem: An open platform for biomedical image analysis. Mol Reprod Dev 82(7-8): 518-529.

25. Rueden CT, Schindelin J, Hiner MC, DeZonia BE, Walter $\mathrm{AE}$, et al. (2017) ImageJ2: ImageJ for the next generation of scientific image data. BMC Bioinformatics 18(1): 529.

26. Erdfelder E, FAul F, Buchner A, Lang AG (2009) Statistical power analyses using $G^{*}$ Power 3.1: Tests for correlation and regression analyses. Behavior Research Methods 41: 1149-1160.

27. Patzelt SBM, Bahat O, Reynolds MA, Strub JR (2014) The All-on-Four Treatment Concept: A Systematic Review. Clin Implant Dent Relat Res 16(6): 836-855.

28. Browaeys H, Defrancq J, Dierens MCA, Miremadi R, Vandeweghe S, et al. (2013) A retrospective analysis of early and immediately loaded osseotite implants in 
cross-arch rehabilitations in edentulous maxillas and mandibles up to 7 Years. Clin Implant Dent Relat Resh 15(3): 380-389.

29. Del Fabbro M, Bellini CM, Romeo D, Francetti L (2012) Tilted Implants for the Rehabilitation of Edentulous Jaws: A Systematic Review. Clin Implant Dent Relat Res 14(4): 612-621.

30. Zechner W, Watzak G, Gahleitner A, Busenlechner D, Tepper G (2003) Rotational panoramic versus intraoral rectangular radiographs for evaluation of peri-implant bone loss in the anterior atrophic mandible. Int J Oral Maxillofac Implants 18(6): 873-878.

31. Van De Velde T, Collaert B, De Bruyn H (2007) Immediate loading in the completely edentulous mandible: Technical procedure and clinical results up to 3 years of functional loading. Clin Oral Implants Res 18(3): 295-303.

32. Collaert B, De Bruyn H (2008) Immediate functional loading of TiOblast dental implants in full-arch edentulous maxillae: A 3-year prospective study. Clinical Oral Implants Research 19(12): 1254-1260.

33. Cooper LF, Raes F, Reside GJ, Garriga JS, Tarrida LG, et al. (2010) Comparison of radiographic and clinical outcomes following immediate provisionalization of single-tooth dental implants placed in healed alveolar ridges and extraction sockets. The International journal of oral \& maxillofacial implants 25(6): 1222-1232.
34. Dierens $M$, Vandeweghe S, Kisch J, Nilner K, de Bruyn $H$ (2012) Long-term follow-up of turned single implants placed in periodontally healthy patients after 16-22 years: Radiographic and peri-implant outcome. Clin Oral Implants Res 23(2): 197-204.

35. Vandeweghe S, Cosyn J, Thevissen E, Van den Berghe L, De Bruyn H (2012) A 1-Year Prospective Study on CoAxis?? Implants Immediately Loaded with a Full Ceramic Crown. Clin Implant Dent Relat Res 14(1): 126-138.

36. Sivasriyanond C, Manson Hing LR (1978) Microdensitometric and visual evaluation of the resolution of dental films. Oral Surgery, Oral Medicine, Oral Pathology 45(5): 811-822.

37. Brägger U, Hugel Pisoni C, Bürgin W, Buser D, Lang NP (1996) Correlations between radiographic, clinical and mobility parameters after loading of oral implants with fixed partial dentures: A 2-year longitudinal study. Clin Oral Implants Res 7(3): 230-239.

38. Lambert PM, Morris HF, Ochi S (1997) Positive effect of surgical experience with implants on second-stage implant survival. J Oral Maxillofac Surg 55: 12-18.

39. Vervaeke S, CollaertB, VandewegheS, Cosyn J, Deschepper E, et al. (2012) The effect of smoking on survival and bone loss of implants with a fluoride-modified surface: A 2-year retrospective analysis of 1106 implants placed in daily practice. Clin Oral Implants Res 23(6): 758-766. 